\title{
Prognostic factors to predict outcome of reduced intensity allogeneic haematopoietic cell transplantation for chronic lymphocytic leukemia
}

\author{
P. JINDRA ${ }^{1,3, *}$, L. RAIDA ${ }^{2}$, D. LYSAK ${ }^{1,3}$, M. KARAS ${ }^{1}$, T. PAPAJIK² , A. JUNGOVA ${ }^{1}$, L. MOHAMMADOVÁ ${ }^{1}$, L. HOUDOVA ${ }^{4}$
}

${ }^{1}$ Dpt. Haematology\&Oncology, UniversityHospitalPilsen, Czech Republic; ${ }^{2}$ Department of Hemato-Oncology, Faculty of Medicine and Dentistry, University Palackianae Olomouc, Czech Republic; ${ }^{3}$ Biomedical Center, Faculty of Medicine in Pilsen, Charles University in Prague, Pilsen, Czech Republic; ${ }^{4}$ University of West Bohemia - Faculty of AppliedSciences, NTIS - New Technologies fortheInformation Society, Pilsen, Czech Republic

${ }^{*}$ Correspondence: jindra@fnplzen.cz

Received December 5, 2015 / Accepted February 29, 2016

\begin{abstract}
Despite advances in immunochemotherapy CLL remains an incurable disease.. Allogeneic haematopoietic cell transplantation (HCT) has proven curative potential with ability to overcome adverse prognostic factors, however due to its toxicity it is generally perceived as the last option. We performed retrospective study to explore the outcomes and possible determinants of survival in the unselected consecutive cohort of 68 CLL patients (median age 59 years) receiving reduced intensity HCT as a part of salvage therapy in 2 Czech centers. The median interval from diagnosis to HCT was 69 months with median 3 of prior regimens, all patients were refractory to purine analogues. $49 \%$ of patients were transplanted with advanced (i.e. refractory or progressive disease or $\mathrm{CR} / \mathrm{PR}>3$ ), 38\% had high risk cytogenetics. With median follow-up of 35 months the 3-year Kaplan-Meier survival probability for OS and PFS were $39 \%$ and 26\%, respectively. Altogether 18 patients (26\%) have relapsed or progressed. During the follow-up 41 patients died, 32 (78\%) of transplant related factors (NRM), the others of relapse or disease progression. Univariate analysis failed to identify any clinical and pre- or post-transplant variables having clear prognostic significance for OS or PFS. The marginal OS advantage favoring HCT performed recently was detected (3-year OS: 31\% for HCT until 2006 and 47\% thereafter, $\mathrm{p}=0.0923$ ). In multivariable hazards model only the female donors were associated with shorter OS (HR 2.278, $\mathrm{p}=0.016$ ) whereas transplanted T-cell $>2.75 \times 10^{8} / \mathrm{kg}$ predicted inferior PFS(HR 1.957, $\mathrm{p}=0.035$ ). No prognostic impact of donor type, age of donor and recipient, HLA mismatch, disease status pre-HCT, number of previous therapy lines, interval from dg. to HCT and number of transplanted hematopoietic cells was found. Our findings support the conclusion that alloHCT is able to overcome well known negative cytogenetic prognostic factors and that preferring male to female donors could be beneficial.
\end{abstract}

Key words: CLL, Allogeneic HCT, RIC, prognostic factors

Highly effective chemoimmunotherapy regimens have significantly improved the outcome of patients with chronic lymphocytic leukemia (CLL) [1-3]. Despite these advances CLL remains an incurable disease and virtually all patients will relapse. However, long-term PFS is possible with allogeneic haematopoietic cell transplantation (HCT) and its curative potential with ability to overcome adverse prognostic factors (namely $17 \mathrm{p}$ abnormalities and unmutatedIgVH) was convincingly demonstrated [4-6]. Because of the high toxicity the procedure was historically limited to the young patients. Advances in supportive care and the advent of reducedintensity conditioning (RIC) regimens allowed to profit from this procedure to older age groups and promising results were published [4-5, 7-9]. However historically there has been reluctance for using unrelated donors as unrelated HCT for older patients has been considered to be compromised with unacceptable high transplant related-mortality. More sophisticated HLA typing and expanded pool of unrelated donors worldwide allowed refinements in the donor selection and recently similar outcomes using related and unrelated donors were reported [4-10]. Although genoidentical sibling is still a donor of choice, the unrelated donors are currently considered equivalent alternative [10].

The heterogeneity of disease behavior raises the question of appropriate indication and timing of HCT. The EBMT consensus criterion recommends allogeneic HCT for younger patients nonresponsive or early relapsing after purine analogues therapy and in patients with $17 \mathrm{p}$ abnormalities [11]. 
However these criteria were formulated on the basis of limited long-term RIC-HCT data and before the advent of highly effective novel therapies.

In an effort to further elucidate this question we have performed retrospective analysis in a cohort of consecutive patients who received allo RIC-HCT in 2 Czech transplant centers. The aim was to evaluate the factors that seemed to be the most significant determinants of HCT outcome in this specific patient group.

Table 1. Characteristics of the patients

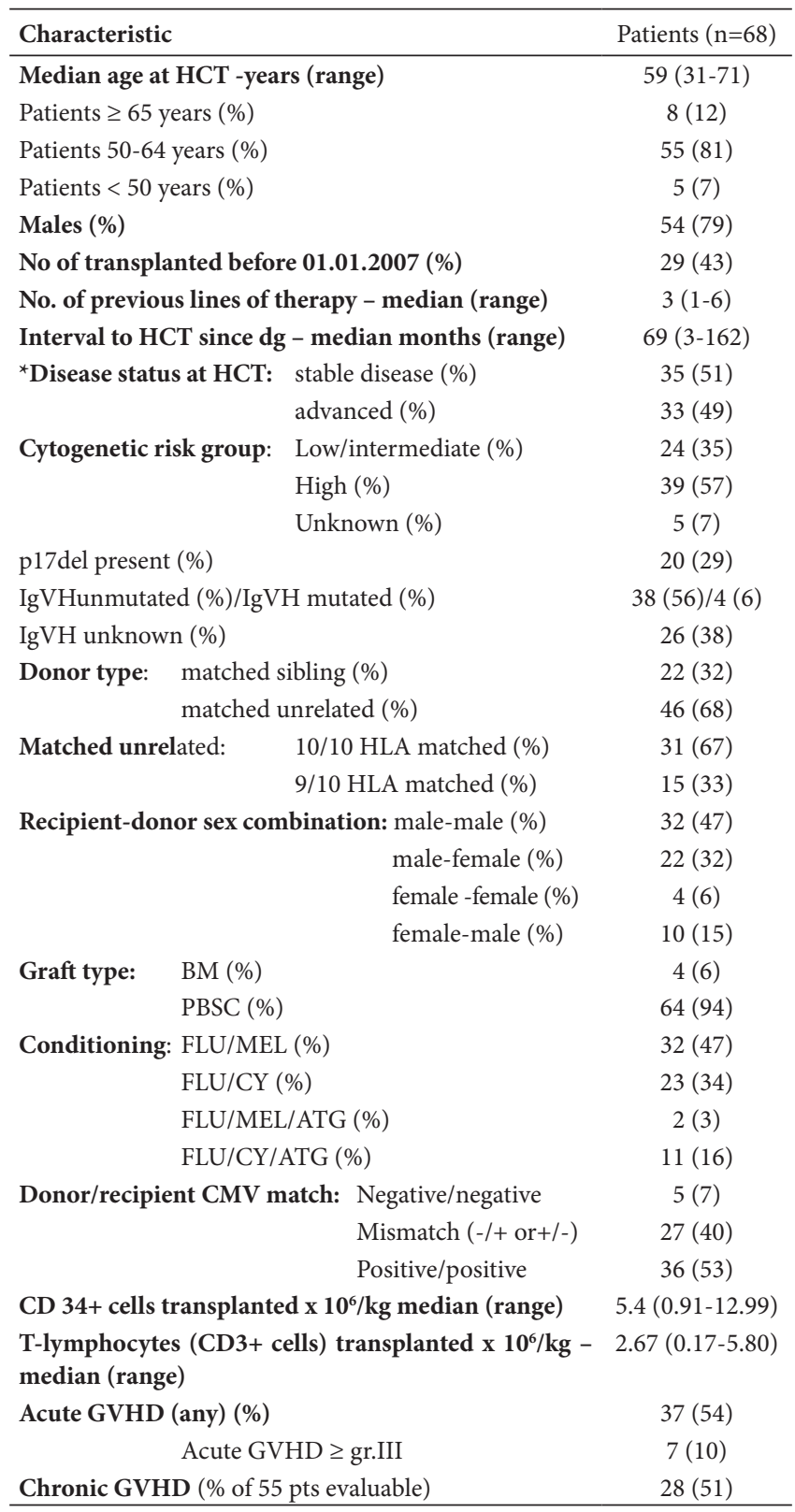

${ }^{*}$ i.e. refractory or progressive disease or $\mathrm{CR} / \mathrm{PR}>3$

\section{Patients and methods}

Patients. This is a retrospective analysis of all consecutive patients with CLL who underwent allogeneic HCT from either related or unrelated donor following RIC conditioning in 2 Czech centers (University Hospital Pilsen and University Hospital Olomouc) between July 2001 and May 2012. Baseline transplant data and post-transplant outcomes were extracted from the institutional transplant databases and the individual medical records of each patient. Altogether 68 consecutive patients transplanted between July 2001 and May 2012 were identified. All patients signed local informed consent for the anonymized analyses of clinical data.

Study definitions and endpoints. Cytogenetics risk status was counted as high for del17p, 11q or complex abnormalities and low for del13q cases. All others were considered as standard cytogenetic risk. Complete remission (CR), partial remissions $(\mathrm{PR})$ stable $(\mathrm{SD})$ and progressive disease (PD) were defined according to the National Cancer Institute Working Group criteria for CLL used at the time these HCT were performed [12]. For analysis the CLL status at the time of HCT was classified as either early $(\mathrm{CR} / \mathrm{PR} \leq 3$, $\mathrm{SD}$ in $<2^{\text {nd }}$ relapse) or advanced $(\mathrm{CR} / \mathrm{PR}>3$, progressive or refractory disease). Primary outcomes were overall survival (OS), progression-free survival (PFS, defined as survival without death, relapse or progression), non-relapse mortality (NRM, defined as any death in continuous remission) and hematologic relapse.

Statistical analysis. Patient characteristics were summarized using frequency tables and standard descriptive statistics. Probabilities of overall survival (OS) and progression-free survival (PFS) were estimated using the Kaplan-Meier method. Univariate analyses to evaluate differences in survival between groups of patients were performed using the log-rank test and Wilcoxon test. The Cox proportional hazards model was considered for the survival modelling to specify the role of individual prognostic factors in assessing the OS and PFS. The multivariable Cox proportional hazards model (stepwise regression) was used for identification of the significant prognostic factors on OS and PFS. Level of statistical significance $a=0.05$ was used in all analyses.All computations were performed using the SAS software (SAS Institute Inc., Cary, NC, USA) and STATISTICA software (StatSoft, Inc., Tulsa, OK, USA).

\section{Results}

Patient characteristics. A total of 68 patients were included. The main pre-transplant characteristics and transplant variables are summarized in table 1 . The median patient age was 59 years (range, 31 to 71 ).

Cytogenetics risk, disease status and other prognostic factors. Cytogenetic data were available for 63 patients (93\%) and $24(38 \%)$ belonged to high risk whereas 9 (14\%) to low risk category. In 9 (14\%) patients del17p was present; TP53 
mutation testing was not performed. IgH mutational status was assessed in 42 patients (62\%) with 38 (90\%) being unmutated.

Disease status. The median interval from diagnosis to HCT was 69 months (range 3-162) with median 3 of prior regimens (range 1-6). All patients were refractory to purine analogues. No patient was being treated with $1^{\text {st }}$ line rituximab, 15 patients (22\%) having received it in $\geq 2^{\text {nd }}$ line of therapy. $54 \%$ of patients were transplanted with stable disease and in $49 \%$ CLL was classified as advanced (i.e. refractory or progressive disease or $\mathrm{CR} / \mathrm{PR}>3$ ).

Donors\&HLAmatching\&stem cell source. Donors were 22 HLA identical siblings and 46 unrelated HLA-A,-B,-C,DR,-DQ completely matched (allelic level by high resolution typing) donors $(10 / 10, \mathrm{n}=35)$ or partially mismatched $(9 / 10$, $\mathrm{n}=11$ ). Peripheral blood stem cells (PBSC) were the stem cell source in all but 4 patients (6\%).

Conditioning, GVHD prophylaxis and treatment. RIC regimens consisted of fludarabine in combination with melphalan or cyclophosphamide. ATG simultaneously with RIC conditioning regimens was used in 13 patients (19\%). GVHD prophylaxis was based on cyclosporine in all patients. Incidences of grades I-IV acute GVHD and chronic GVHD were determined according the established criteria $[13,14]$. Chronic GVHD was evaluated in patients who survived at least 100 days with sustained engraftment.

Survival. With median follow-up of surviving patients of 35 months (range 6 - 110) the 3-year Kaplan-Meier survival probability estimated for OS and PFS were $39 \%$ and $26 \%$, respectively (Figure 1). Altogether 18 patients (26\%) have relapsed or progressed. During the follow-up 41 patients died, $32(78 \%)$ of transplant related factors (NRM), the others of relapse or disease progression.
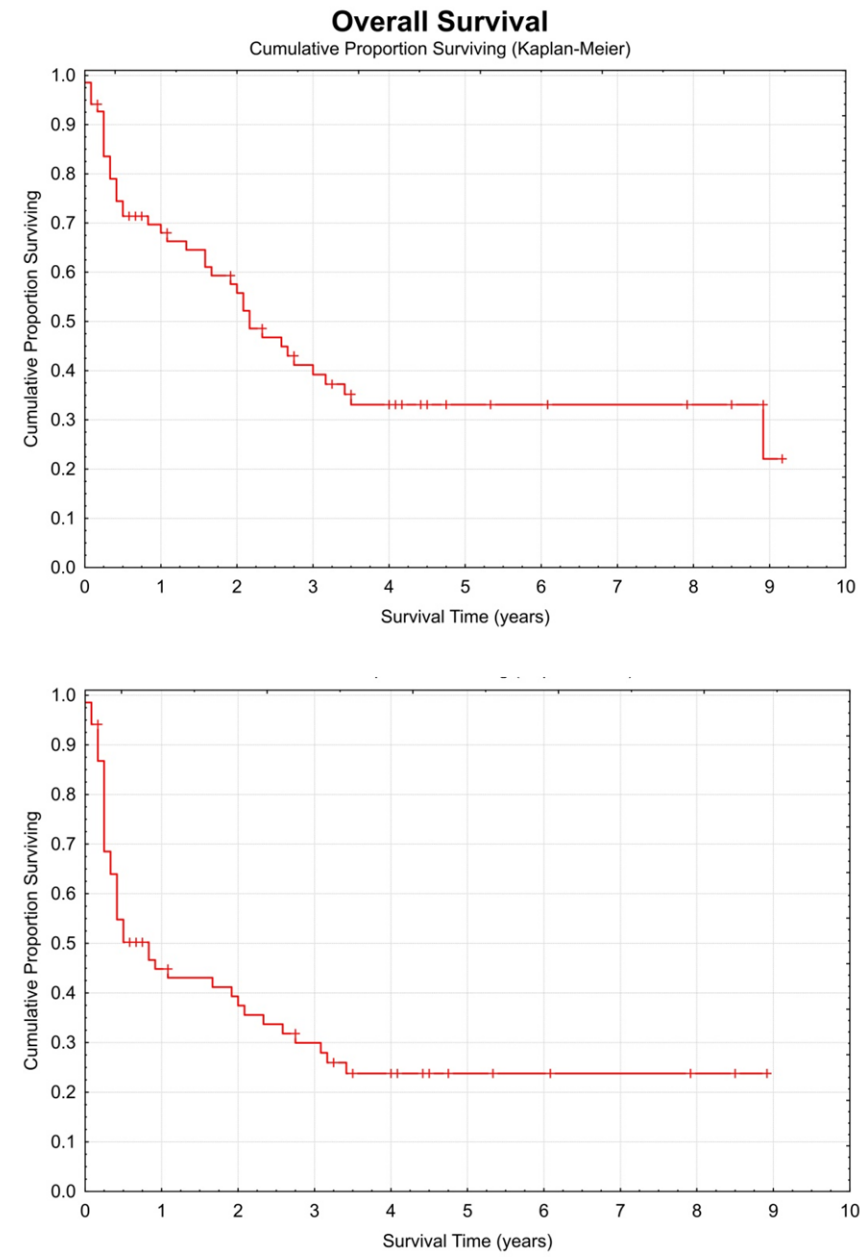

Figure 1. Overall and progression free survival of all patients

Table 2. Prognostic factors for OS and PFS

\begin{tabular}{|c|c|c|c|c|c|c|}
\hline \multirow[b]{2}{*}{ Prognostic factor } & \multicolumn{3}{|c|}{ OS } & \multicolumn{3}{|c|}{ PFS } \\
\hline & HR & $95 \%$ CI & $\mathbf{P}$ & HR & $95 \%$ CI & $\mathbf{P}$ \\
\hline \multicolumn{7}{|l|}{ Univariate analysis } \\
\hline Patient age (years) & 1.34 & $(0.92-1.86)$ & 0.361 & 1.27 & $(0.90-1.94)$ & 0.397 \\
\hline Poor risk cytogenetics & 1.30 & $(0.96-2.55)$ & 0.410 & 1.23 & $(0.94-2.13)$ & 0.487 \\
\hline Del p17 & 1.49 & $(1.15-2.33)$ & 0.253 & 1.24 & $(0.89-2.53)$ & 0.496 \\
\hline Disease status at HCT - advanced disease & 1.63 & $(1.09-2.84)$ & 0.117 & 1.06 & $(0.86-1.56)$ & 0.826 \\
\hline$>3$ lines of treatment pre-HCT & 0.97 & $(0.79-1.38)$ & 0.928 & 1.21 & $(0.89-1.82)$ & 0.531 \\
\hline Interval dg. to HCT > 5 years & 0.88 & $(0.53-1.45)$ & 0.675 & 0.86 & $(0.51-1.40)$ & 0.595 \\
\hline Unrelated donor & 0.72 & $(0.51-1.28)$ & 0.288 & 0.65 & $(0.39-1.26)$ & 0.143 \\
\hline Donor age $>35$ years & 1.34 & $(0.87-1.92)$ & 0.361 & 1.27 & $(0.85-1.89)$ & 0.397 \\
\hline Donor sex - female & 1.78 & $(1.03-2.68)$ & 0.071 & 1.74 & $(1.02-2.61)$ & 0.064 \\
\hline Number of CD34+ cells transplanted $>5.5 \times 10^{6} / \mathrm{kg}$ & 0.70 & $(0.48-1.60)$ & 0.274 & 0.95 & $(0.61-1.64)$ & 0.867 \\
\hline Number of T-cells $(\mathrm{CD} 3+)$ transplanted $>2.75 \times 10^{8} / \mathrm{kg}$ & 1.71 & $(0.88-2.88)$ & 0.085 & 1.69 & $(0.97-2.76)$ & 0.066 \\
\hline HLA mismatch & 1.53 & $(0.95-2.34)$ & 0.238 & 0.99 & $(0.69-1.58)$ & 0.966 \\
\hline \multicolumn{7}{|l|}{ Multivariable analysis } \\
\hline Donor sex - female & 2.278 & $(1.17-4.44)$ & 0.016 & - & & \\
\hline Number of T-cells $(\mathrm{CD} 3+)$ transplanted $>2.75 \times 10^{8} / \mathrm{kg}$ & - & & & 1.96 & $(1.05-3.65)$ & 0.035 \\
\hline
\end{tabular}


Acute and chronic GVHD. The overall incidence of acute GVHD was $54.4 \%$, whereas the incidence of grades III-IV aGVHD was $10.3 \%$.In 55 evaluable patients the overall incidence of chronic GVHD was $50.9 \%$ and $32.7 \%$ for extensive GVHD.

Prognostic factors for survival. Univariate analysis failed to identify any clinical and pre- or post-transplant variables having clear prognostic significance for OS or PFS. Table 2 summarizes all variables tested. Only grafts with $>2.75 \times 10^{8}$ T-cells were marginally associated with worse OS and PFS (HR 1.71, $\mathrm{p}=0.085$ and HR 1.69, $\mathrm{p}=0.0656$, respectively). The marginal worse OS and PFS was also noted for female donors (HR 1.78, $\mathrm{p}=0.0716$ and $1.74, \mathrm{p}=0.0642$, respectively). Conversely, patient age, stage of the disease, cytogenetic risk, presence of del p17 were not predictive of OS/PFS (Fig 2). Likewise, a similar survival outcome was observed in patients with related or unrelated donor. To unveil possible association of main outcomes with the year of HCT we looked at
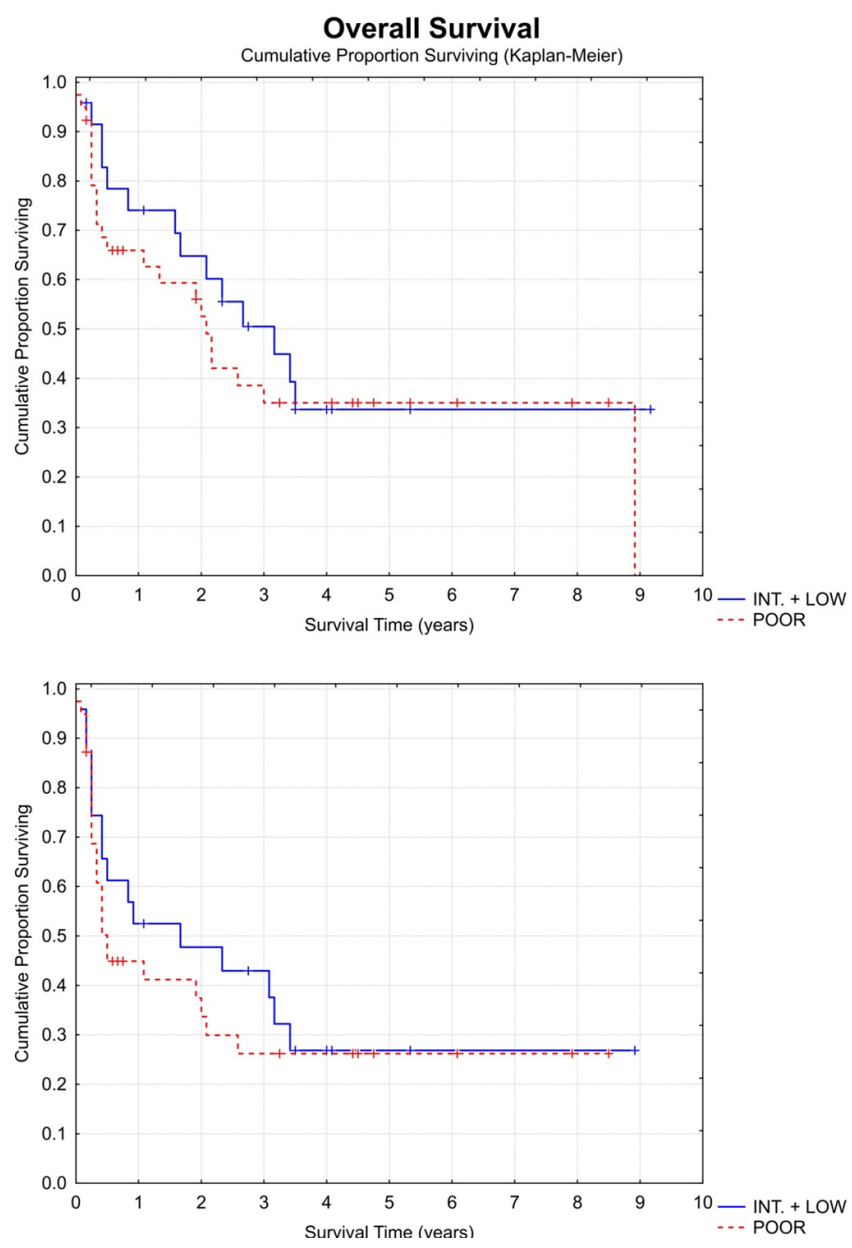

Figure 2. Overall survival and progression free survival according to cytogenetic risk (high risk $=$ del17p, $11 \mathrm{q}$ or complex abnormalities, and low risk $=$ del13q cases, all others are considered as intermediate cytogenetic risk)
HCT performed until 2006 and thereafter. The marginal OS advantage favoring HCT performed later was detected (3-year OS: $31 \%$ for HCT until 2006 and $47 \%$ thereafter, $p=0.0923$ ) with the suggestion that this was primarily due to lower NRM after 2006 compared with earlier time period (3-year cumulative incidence of NRM $62 \%$ for transplanted until 2006 vs. $36 \%$ transplanted after 2006, $\mathrm{p}=0,0912$ ). All other variables between these groups were similar (data not shown).

In multivariable analysis (Table 2) only the female donors were associated with shorter OS (HR 2.278, $\mathrm{p}=0.016$ ) whereas transplanted T-cell $>2.75 \times 10^{8} / \mathrm{kg}$ predicted inferior PFS (HR 1.957, $\mathrm{p}=0.035$ )

\section{Discussion}

Despite introduction of highly effective new therapies in CLL, allogeneic stem cell transplantation is still considered as the only provencurative treatment [4-11]. However due to its toxicity it is generally perceived as the last option. In our retrospective study we explored the outcomes and possible determinants of survival in the unselected consecutive cohort of CLL patients that received RIC-HCT as a part of salvage therapy.We demonstrate that RIC-HCT in our study group cohort of patients provides sustained 3 year probability of overall survival/progression free survival in $39 / 26 \%$ of transplanted patients.

Compared with prior studies - both prospective and retrospective, myeloablative or nonmyeloablative - we observed lower survival data $[4-5,8-10,15]$. The key series of RIC alloHCT have reported overall survival within range 50-60\% and PFS within range $36-43 \%[4-5,8,15]$.This was caused predominantly by higher non-relapse mortality in our study ( $47 \%$ cumulative incidence versus $16-23 \%$ that were reported elsewhere) $[4-5,8,15]$. However our study differs in some key variables. The cited studies have significantly lower proportion of purine analog refractory patients - from $47 \%$ in Dreger study [4] to $87 \%$ in Sorror study [15] whereas in our cohort all patients were purine analog refractory. Also the proportion of patients with refractory/progressive disease at HCT differs in majority of comparable studies. Except for the study of Sorror et al which contains $55 \%$ of disease refractory patients [15] all other comparable studies have lower numbers than $49 \%$ in our cohort $[4-5,8]$. Finally, the inferior survival data in our study could be partly related to higher median age of our cohort in contrast to other reports (59 years vs. 53-58 years) $[4-5,8,15]$. Moreover we included highest fraction of patients $>65$ years and the lowest fraction of patients $<50$ years of age. For example the study of Brown et al included $8 \%$ of patients $>65$ years and $29 \%<50$ years of age [8] whereas corresponding figures for our study was $12 \%$ and $7 \%$, respectively. It is reassuring, we have observed trend for better survival for those patients transplanted after 2006 ( $31 \%$ versus $48 \%$ at 3 year, $\mathrm{p}=0,0923$ ) despite the groups have no difference in main variables (data not shown). Sorror et al have found that lymph node size $\geq 5$ $\mathrm{cm}$ and HCT CI score $\geq 1$ predicts inferior OS [15]. Unfortu- 
nately we are unable to incorporate those variables into our analyses because of missing data in majority of patients.

In accordance with others the presence of poor risk cytogenetics (including del p17) did not influence outcomes [4, 5, $8,15]$ and the same was true for use of unrelated, even mismatched donor, age of the donor and number of transplanted CD34+ cells (table 2).

The multivariate analysis reveals unexpected findings, the female donors were significantly associated with inferior OS (HR 2.278; CI 1.17-4.44; $\mathrm{p}=0.016$ ). Stern et al. suggested that male aplastic anemia patients transplanted with female donors had significantly decreased survival and best outcome is achieved in patients with donor from the same sex [16]. Small number of our pairs (see table1) limits the ability to confirm the hypothesis that sex matching is beneficial in RIC allografted CLL patients. Our data from multivariable analysis also provide evidence that patients transplanted with T-cells $(\mathrm{CD} 3+)>2.75 \times 10^{8} / \mathrm{kg}$ have inferior PFS (HR 1.96; CI 1.05-3.65; $\mathrm{p}=0,035)$. We do not have clear explanation for this and published data are scarce. Khouri et al did not observe any association with number of CD3+ cells transplanted and outcome [5] and other studies did not analyze this variable. The relapse rates as well as rates of acute and chronic GVHD between transplanted with $>2,75 \mathrm{CD} 3 \times 10^{8} / \mathrm{kg}$ were not different comparing to opposite group, the only difference was in NRM rate (60\% versus $35 \%)$. The relative small number of patients and heterogeneity of grafts (related and unrelated, male and females, few were bone marrow grafts) impedes reasonable explanation and all possible conclusion would be speculative.

Our analysis is a retrospective study with all its inherent limitations, i.e. mainly natural susceptibility to bias in patient selection and heterogeneity of data. On the other hand it represents the real life experience of patients referred to alloHCT according the EBMT recommendations outside the artificial conditions in the trials. Also the highest median age among published studies more accurately reflects reality of typical CLL patient.

In conclusion, our finding supports the conclusions that alloHCT is able to overcome well known negative cytogenetic prognostic factors (fig. 2), especially del17p, and thus confirms available data $[4-6,8-10,15]$. We did not find any prognostic impact of donor type, age of donor and recipient, HLA mismatch, disease status pre-HCT, number of previous therapy lines, interval from dg. to HCT and number of transplanted hematopoietic cells. On the contrary our data suggest that preferring male to female donors would be beneficial. However the significant transplant related mortality should be taken into account and available promising data for inhibitors of B-cell receptor kinases (ibrutinib, idelalisib) challenged the current place of HSCT in treatment algorithms for CLL.

Notwithstanding that, alloHCT still remains the only proven curative treatment for (ultra) high-risk CLL patient $[11,17,18]$ and ultimate impact of novel agents modifying the role of HCT in the management of such patients has to be defined. Data so far suggests that alloHCT will continue to have important place in the management of high-risk CLL patients especially in case of BCR inhibitors failure [18].

Acknowledgements: The study was supported in part by the grants of Ministry of Health 15-30661A, 15-25809A, by the grant TA ČR TA04010727 and by the following projects: project for conceptual development of research organization 00669806 (Faculty Hospital in Plzen, Czech Republic), project IGA-LF-2015-001 of Palacky University in Olomouc, project LO1506 of the Czech Ministry of Education, Youth and Sports and by the National Sustainability Program I (NPU I) Nr. LO1503 provided by the Ministry of Education Youth and Sports of the Czech Republic.

\section{References}

[1] KEATING MJ, FLINN I, JAIN V, BINET JL, HILLMEN P et al. Therapeutic role of alemtuzumab (Campath-1H) in patients who have failed fludarabine: results of a large international study. Blood2002; 99: 3554-3561. http://dx.doi.org/10.1182/ blood.V99.10.3554

[2] HALLEK M, FISCHER K, FINGERLE-ROWSON G et al. on behalf of German Chronic Lymphocytic Leukaemia Study Group. Addition of rituximab to fludarabine and cyclophosphamide in patients with chronic lymphocytic leukaemia: a randomised, open-label, phase 3 trial.Lancet 2010; 376: 1164-1174 http://dx.doi.org/10.1016/S0140-6736(10)61381-5

[3] FISCHER K, CRAMER P, BUSCH R, STILGENBAUER S, BAHLO J et al. Bendamustine combined with rituximab in patients with relapsed and/or refraktory chronic lymphocytic leukemia: a multicenter phase II trial of the German Chronic Lymphocytic Leukemia Study Group. J Clin Oncol 2011; 29: 3559-3566. http://dx.doi. org/10.1200/JCO.2010.33.8061

[4] DREGER P, DOHNER H, RITRGEN M, BOTCHER S, BUSCH R, et al. Allogeneic stem cell transplantation provides durable disease control in poor-risk chronic lymphocytic leukemia: long-term clinical and MRD results of the German CLL Study Group CLL3X trial. Blood 2010; 116: 2438-2447 http://dx.doi.org/10.1182/blood-2010-03-275420

[5] KHOURI, IF, BASSETT R, POINDEXTER N, O'BRIENS, BUESO-RAMOS CE et al. Nonmyeloablative allogeneic stem cell transplantation in relapsed/refractory chronic lymphocytic leukemia: long-Term Follow-Up, Prognostic Factors, and Effect of Human Leukocyte Histocompatibility Antigen Subtype on Outcome. Cancer 2011; 117: 4679-4688. http:// dx.doi.org/10.1002/cncr.26091

[6] SCHETELIG J, VAN BIEZEN A, BRAND R, CABALLERO D, MARTINO R, et al.Allogeneic hematopoietic stem-cell transplantation for chronic lymphocytic leukemia with $17 \mathrm{p}$ deletion: a retrospective European Group for Blood and Marrow Transplantation analysis. J ClinOncol2008; 26: 5094-5100. http://dx.doi.org/10.1200/JCO.2008.16.2982

[7] GOOLEY, TA, CHIEN, JW, PERGAM SA, HINGORANI S, SORROR ML, et al. Reduced mortality after allogeneic hematopoietic-cell transplantation. New England Journal of 
Medicine 2010; 363: 2091-2101. http://dx.doi.org/10.1056/ NEJMoa1004383

[8] BROWN JR, KIM HT, ARMAND P, CUTLER C, FISHER DC et al. Long-term follow-up of reduced-intensity allogeneic stem cell Transplantation for chronic lymphocytic leukemia: prognostic model to predict outcome. Leukemia2013; 27: 362-369. http://dx.doi.org/10.1038/leu.2012.228

[9] TOZE CL, DALA CB, NEVILL TJ, GILLAN TL, ABOUMOURADYR,ET AL. Allogeneic haematopoietic stem cell transplantation for chronic lymphocytic leukaemia: outcome in a 20-year cohort. Br J Haematol 2012; 158: 174-185. http://dx.doi.org/10.1111/j.1365-2141.2012.09170.x

[10] MICHALLET M, SOBH M, MILLIGAN D, MORISSET S, NIEDERWIESER D et al. The impact of HLA matching on long-term transplant outcome after allogeneic hematopoietic stem cell transplantation for CLL: a retrospective study fromthe EBMT registry. Leukemia2010; 24: 1725-1731. http:// dx.doi.org/10.1038/leu.2010.165

[11] DREGER P, CORRADINI P, KIMBY E, MICHALLET M, MILLIGAN D et al. Indications for allogeneic stem cell transplantation in chronic lymphocytic leukemia: the EBMT transplant consensus. Leukemia2007; 21: 12-17. http://dx.doi. org/10.1038/sj.leu.2404441

[12] CHESON BD, BENNET JM, GREVER M, KAY N, KEATING MJ, et al.National Cancer Institute -sponsored Working group guidelines for chronic lymphocytic leukemia: revised guidelines for diagnosis and treatment. Blood 1996; 87: 4990-4997.

[13] FILIPOVICH AH, WEISDORF D, PAVLETIC S, SOCIE G, WINGARD JR, et al. National Institute of Health consensus development project on criteria for clinical trials in chronic graft-versus-host disease: I. Diagnosis and Staging Working Group report. Biol Blood Marrow Transplant 2005; 11: 945-956. http://dx.doi.org/10.1016/j.bbmt.2005.09.004

[14] PRZEPIORKA D, WEISDORF D, MARTIN P, KLINGEMANN HG, BEATTY P, et al. 1994 Consensus Conference on Acute GVHD Grading. Bone Marrow Transplant 1995; 15: 825-828.

[15] SORROR ML, STORER BE, SANDMAIER B, MARIS M, SHIZURU J et al. Five-year follow-up of patients with advanced chronic lymphocytic leukemia treated with allogeneic hematopoietic cell transplantation after nonmyeloablative conditioning. J Clin Oncol 2008; 26: 4912-4920. http://dx.doi. org/10.1200/JCO.2007.15.4757

[16] STERN M, PASSWEG, JR, LOCASCIULLI A, SOCIEG, SCHREZENMEIER H, et al. Influence of Donor/Recipient Sex Matching on Outcome of Allogeneic Hematopoietic Stem Cell Transplantation for Aplastic Anemia. Transplantation 2006; 82: 218-226. http://dx.doi.org/10.1097/01. tp.0000226156.99206.d1

[17] ZENZ T, GRIBBEN JG, HALLEK M, DOHNER H, KEATING MJ, et al. Risk categories and refractory CLL in the era of chemoimmunotherapy.Blood 2012; 119: 4101-4107. http:// dx.doi.org/10.1182/blood-2011-11-312421

[18] DREGER P, SCHETELIG J, ANDERSEN N, CORRADINI P, VAN GELDER M, et al. Managing high-risk CLL during transition to a new treatment era: stem cell transplantation or novel agents? Blood 2015; 124: 3841-3849. http://dx.doi. org/10.1182/blood-2014-07-586826 